\title{
The Freeze-Thaw Resistance of Concrete Control Structure for Debris Flow on Tianshan Highway HUANG-Yong ${ }^{1,2, a}$, XU Huining ${ }^{* 3, b}$, CHEN-Hongkai ${ }^{4, c}$
}

\author{
${ }^{1}$ State Key Laboratory of Geological Hazard Prevention and Geological Environment Protection, \\ Chengdu University of Technology, Chengdu 610059, China; \\ ${ }^{2}$ Xinjiang Traffic Science Institute of Communication, Urumqi 830000, China; \\ ${ }^{3}$ Harbin Institute of Technology, Nangang District, 92 Xidazhi Street, Harbin 150001, China; \\ ${ }^{4}$ Chongqing Jiaotong University, 66 Xuefu Avenue, Chongqing 400074, China \\ a476786514@qq.com, bemail: xhn1983@163.com, cchk99@163.com
}

${ }^{*}$ Corresponding author: XU Huining

Key Words:Tianshan Highway; Debris Flows; Concrete Structure; Freeze-Thaw

\begin{abstract}
The extreme climate in Tianshan area has a significant impact on the freeze-thaw resistance of concrete control structure for debris flow. This paper describes a fiber reinforced concrete designed for Tianshan area. The impact factors on the freeze-thaw resistance of concrete are analyzed. The optimal composition for concrete control structure is discussed. And the engineering economic of such material is compared with that of Portland cement concrete. Research results shows fiber reinforced concrete can greatly improve the freeze-thaw resistance of concrete, and significantly extend its life with a great of practical value.
\end{abstract}

\section{Introduction}

Tianshan Mountains located in the Northwest of China, belongs to warm areas and boreal-arid areas, poor relief, the temperature changes. Polar minimum temperature is up to $-35^{\circ} \mathrm{C}$, the average winter temperature is $-12.2^{\circ} \mathrm{C}$, and the winter period will last as long as 4 to 6 months. As the long cold winter season, it brought a lot of problems for the project construction. After freezing and thawing, concrete often happens internal cracking, surface sapling, its quality and intensity decreased significantly; seriously affect the structure of using safety reduction its serviceable life. Thus, study on the corresponding concrete debris flow control structures in the area of anti-freeze-thaw performance and enhance its anti-freeze-thaw method of performance have also become a highway construction and maintenance of a key issue.

\section{Research ideas}

Antifreeze is able the concrete to harden in the negative temperature, and achieve the desired performance under the provided conditions. The affection of freeze-thaw on concrete is strong, because of the specificity environment on Tianshan area. Freeze-thaw resistance, anti-cracking performance and its dense closely related fibers crack resistance. The study plans to use to add fly ash, fiber, antifreeze and other ways to improve the concrete of the antifreeze. By comparing the ordinary cement concrete, freeze-thaw resistance of different fibers and antifreeze amount concrete, and drawn the affection of concrete for freeze-thaw resistance from fibers antifreeze content and the relations between amount content and anti-freeze-thaw concrete ,finally the conclusion that the amount fibers and antifreeze optimal mix. 


\section{Construction of test model}

\subsection{Raw material selection}

Necessary indicators of raw materials for the tests are as follows: (1) cement (C): P325 ordinary Portland cement; (2) natural sand (S): (3) middle sand, fineness modulus 2.7; (4) gravel (G): diameter $5 \mathrm{~mm} \sim 20 \mathrm{~mm}$, well-graded; (5) antifreeze: FJW-14 composite antifreeze; (6) super plasticizer: with the series of antifreeze super plasticizer, by the same water rate and antifreeze; (7) Fiber: polypropylene fiber, length of $12 \mathrm{~mm}$; (8) Fly: II -class fly ash.

\subsection{Test Options}

According to "Design Manual of Concrete Mix" select raw materials and mix design, combined with the control structures features of debris flow on Tianshan highway, selecting the design strength grade of concrete is C30, each group shown in Table 1.

Table 1 Ratio of concrete specimen

\begin{tabular}{|c|c|c|c|c|c|c|c|c|}
\hline Test ID & $\begin{array}{c}\text { Cement } \\
{[\mathrm{kg}]}\end{array}$ & $\begin{array}{l}\text { Sand } \\
{[\mathrm{kg}]}\end{array}$ & $\begin{array}{c}\text { Lithotripsy } \\
{[\mathrm{kg}]}\end{array}$ & $\begin{array}{l}\text { Water } \\
{[\mathrm{kg}]}\end{array}$ & $\begin{array}{c}\text { Fly Ash } \\
{[\mathrm{kg}]}\end{array}$ & $\begin{array}{c}\text { Cryoprotectants } \\
{[\%]}\end{array}$ & $\begin{array}{c}\text { Fiber } \\
{[\%]}\end{array}$ & $\begin{array}{c}\text { Super plasticizer } \\
{[\%]}\end{array}$ \\
\hline $\mathrm{S}$ & 313 & 595 & 1264 & 162 & 66 & 1 & 1 & 1 \\
\hline A1 & 313 & 595 & 1264 & 162 & 66 & 4 & 0.3 & / \\
\hline B1 & 313 & 595 & 1264 & 162 & 66 & 4 & 0.4 & 1 \\
\hline $\mathrm{C} 1$ & 313 & 595 & 1264 & 162 & 66 & 4 & 0.6 & 1 \\
\hline A2 & 313 & 595 & 1264 & 162 & 66 & 5 & 0.3 & 1 \\
\hline $\mathrm{B} 2$ & 313 & 595 & 1264 & 162 & 66 & 5 & 0.4 & 1 \\
\hline $\mathrm{C} 2$ & 313 & 595 & 1264 & 162 & 66 & 5 & 0.6 & 1 \\
\hline A3 & 313 & 595 & 1264 & 162 & 66 & 6 & 0.3 & 1 \\
\hline B3 & 313 & 595 & 1264 & 162 & 66 & 6 & 0.4 & 1 \\
\hline $\mathrm{C} 3$ & 313 & 595 & 1264 & 162 & 66 & 6 & 0.6 & 1 \\
\hline
\end{tabular}

The sample size is $100 \mathrm{~mm} \times 100 \mathrm{~mm} \times 100 \mathrm{~mm}$, each group has 3 samples, a total of 30 group specimens. Using artificial mixing produces concrete specimen, the mixing concrete put into steel, vibration molding, add standard conservation.

\subsection{Experimental study on freeze-thaw resistance of concrete}

\subsubsection{Test program of freeze-thaw resistance}

According to the "ordinary concrete long-term performance and durability testing methods" (GBJ82-1985) implementation, using slow freezing and thawing froze Act. During the trial test is divided into three aspects: (1) All samples of the compressive strength of the standard conservation 28d; (2) freeze-thaw samples before freezing and thawing, after freezing and thawing 25 times the sample quality and strength; (3) the compressive strength of freezing and thawing test pieces.

\subsubsection{Analysis of test data}

(1)Benchmark specimen strength of $28 \mathrm{~d}$

$28 \mathrm{~d}$ compressive strength of concrete was measured in each group (Table 2).

Table 2 Specimen baseline strength test for $28 \mathrm{~d}$

\begin{tabular}{ccccc}
\hline Specimen No & \multicolumn{3}{c}{ Compressive strength [MPa] } & The representative value [MPa] \\
\hline S & 31.7 & 32.6 & 33.4 & 32.57 \\
\hline A1 & 32.9 & 34.6 & 33.8 & 33.77 \\
\hline A2 & 34.7 & 33.7 & 36.2 & 34.87 \\
\hline A3 & 34.8 & 33.8 & 35.4 & 34.67 \\
\hline B1 & 35.8 & 33.0 & 30.9 & 33.23 \\
\hline B2 & 33.2 & 35.8 & 30.4 & 33.13 \\
\hline B3 & 31.9 & 31.3 & 29.2 & 29.80 \\
\hline C1 & 29.4 & 29.9 & 30.1 & 30.83 \\
\hline C2 & 30.5 & 31.4 & 30.6 & 31.40 \\
\hline C3 & 26.5 & 32.6 & 31.4 &
\end{tabular}


Concrete compressive strength is the trend of downward. Apart from individual points (4\%ofiber content $6 \%$ antifreeze), other points of strength with the volume change antifreeze range small, amount of antifreeze can be seen for a relatively small impact on the strength of concrete. Antifreeze content of $6 \%$, the concrete compressive strength of a larger magnitude of changes, trends vary uncertainties more.

Different fiber content of the larger changes in the strength of concrete, up to 4mpa, therefore, the impact of fiber on the compressive strength of concrete is significant. Fiber content is $3 \%$, antifreeze content is $5 \%$, the compressive strength of concrete is the highest, antifreeze content is $6 \%$, its strength is in a slightly lower intensity; fiber content is $4 \%$, compressive of concrete volume is in the antifreeze $4 \%$,obtain the maximum intensity is $6 \%$, it may be in a larger attenuation; fiber content in the $5 \%$, the compressive strength of concrete in the antifreeze content of $6 \%$,obtain the maximum, minimum 4\% Department, and three The difference between values is not great. When the fiber content is up to $5 \%$, compressive strength is far less than other samples, and observes the specimen, fiber distributed unevenly, and the fiber content unsuitable $5 \%$.

(2)Strength loss rate of freeze-thaw specimen

By 25 times of freeze-thaw cycle, the freeze-thaw test piece, the test items of compressive strength is in Table 3. This shows that the number for the S concrete strength loss rate of $14.72 \%$ of all samples of the maximum intensity of the loss, mixing fibers and antifreeze can significantly improve the performance of concrete antifreeze. $\Delta \mathrm{F}_{\mathrm{cmax}}=14.72 \%$, far less than $25 \%$, indicating that the sample can withstand repeated freeze-thaw cycles.

Table 3 The record of loss rate for freeze-thaw cycles 25 times about strength

\begin{tabular}{cccc}
\hline Specimen No. & After the freeze-thaw [MPa] & Before the freeze-thaw [MPa] & Strength loss rate [\%] \\
\hline S & 30.87 & 36.20 & 14.72 \\
\hline A1 & 32.2 & 36.93 & 12.81 \\
\hline A2 & 32.47 & 36.87 & 11.93 \\
\hline A3 & 32.77 & 35.43 & 7.51 \\
\hline B1 & 33.13 & 37.67 & 12.05 \\
\hline B2 & 32.87 & 36.86 & 10.82 \\
\hline B3 & 32.60 & 34.50 & 5.51 \\
\hline C1 & 32.03 & 35.77 & 10.46 \\
\hline C2 & 32.37 & 35.80 & 9.58 \\
\hline C3 & 34.10 & 35.90 & 5.01 \\
\hline
\end{tabular}

When the fiber content certain, the strength of concrete with antifreeze loss rate showed a significant increase in volume decline. Fiber content is $3 \%$, the antifreeze content is $4 \%$, when the intensity of the biggest losses, $5 \%$ loss of slightly lower intensity, $6 \%$ dropped, when the intensity of the loss; fiber content is $4 \%$, the antifreeze content is $4 \%$ to obtain the maximum intensity of $6 \%$ when the smallest loss; fiber content is $5 \%$, the antifreeze content is $4 \%$ to get a maximum, minimum 6 percent. With the freeze-thaw damage and lower fiber content an increase that is doped fiber strength loss of concrete freezing and thawing significantly weaken the role. Curve similar to the three parallel, and antifreeze content from $5 \%$ to $6 \%$, when the mass loss of a significant reduction of compressive strength attenuation lesser extent, different fiber content of freeze-thaw loss of strength followed by size: $3 \%_{0}>4 \%>5 \%$. The results show that the fiber content has an important effect on the strength of concrete undergoing the freeze-thaw cycle. The main reason is the combined effects of fiber reinforced flexible network skeleton.

Maintaining the same amount of antifreeze, fiber content increase by $3 \%$, $4 \%$, $5 \%$, the strength of concrete increases, when the fiber content loss. Fiber content unchanged, antifreeze content will grow from $5 \%$ to $6 \%$, the strength of concrete will fall in a sharp losses. With the increasing amount of antifreeze compound, concrete primer gas also increased, these bubbles uniformly distributed in concrete and isolated and cut off the pores road, slowing the expansion of concrete when cold changes, thereby, it will improve the concrete of frost resistance significantly . Antifreeze content is $6 \%$, the strength of concrete loss lower than $4 \%, 5 \%$, different content of freeze-thaw about intensity of antifreeze followed by the size of the loss rate: $4 \%>5 \%>6 \%$. 


\section{(3)Mass loss rate of freeze-thaw specimen}

Concrete due to freeze-thaw erosion by frost heave pressure cracking, spilling produce mass loss, while structural damage of strength reduction is to speed up, it seriously affects the use of structures security. Through the analysis of freezing and thawing frozen samples before and after the quality, mass loss is from the maximum value for the S group of concrete $(0.32 \%)$, far less than $5 \%$.All the concrete mix can withstand many freeze-thaw cycle times (Table 4).

Table 4 The mass loss rate and freeze-thaw specimen

\begin{tabular}{ccccccccccc}
\hline & \multicolumn{3}{c}{ 1 } & \multicolumn{3}{c}{ 2 } & \multicolumn{3}{c}{ 3 } & Loss rate \\
\cline { 2 - 13 } No. & $\begin{array}{c}\text { Original } \\
\text { Quality }\end{array}$ & $\begin{array}{c}\text { Freezing } \\
\text { Quality }\end{array}$ & Loss & $\begin{array}{c}\text { Original } \\
\text { Quality }\end{array}$ & $\begin{array}{c}\text { Freezing } \\
\text { Quality }\end{array}$ & Loss & $\begin{array}{c}\text { Original } \\
\text { Quality }\end{array}$ & $\begin{array}{c}\text { Freezing } \\
\text { Quality }\end{array}$ & Loss & {$[\%]$} \\
\hline S & 2.446 & 2.438 & 0.008 & 2.47 & 2.461 & 0.009 & 2.476 & 2.469 & 0.007 & 0.32 \\
\hline A1 & 2.435 & 2.445 & 10 & 2.435 & 2.429 & 0.006 & 2.475 & 2.485 & 10 & 0.25 \\
\hline A2 & 2.445 & 2.443 & 0.002 & 2.47 & 2.461 & 0.009 & 2.475 & 2.508 & 33 & 0.22 \\
\hline A3 & 2.426 & 2.42 & 0.006 & 2.388 & 2.385 & 0.003 & 2.427 & 2.425 & 0.002 & 0.15 \\
\hline B1 & 2.545 & 2.559 & 14 & 2.485 & 2.479 & 0.006 & 2.41 & 2.42 & 10 & 0.24 \\
\hline B2 & 2.41 & 2.404 & 0.006 & 2.418 & 2.416 & 0.005 & 2.384 & 2.4 & 16 & 0.23 \\
\hline B3 & 2.38 & 2.377 & 0.003 & 2.47 & 2.464 & 0.006 & 2.368 & 2.365 & 0.003 & 0.17 \\
\hline C1 & 2.473 & 2.471 & 0.002 & 2.4 & 2.395 & 0.005 & 2.373 & 2.367 & 0.006 & 0.18 \\
\hline C2 & 2.42 & 2.418 & 0.002 & 2.444 & 2.454 & 10 & 2.395 & 2.387 & 0.008 & 0.21 \\
\hline C3 & 2.453 & 2.45 & 0.003 & 2.49 & 2.485 & 0.005 & 2.486 & 2.482 & 0.004 & 0.16 \\
\hline
\end{tabular}

When fiber content decreases; antifreeze content is $6 \%$, the mass loss of the maximum value appears in $4 \%$, and the minimum value is still achieved in $5 \%$. Mass rate of concrete will Loss, when the fiber content increases. Fiber content for is $4 \%, 5 \%$, the mass loss of concrete changes are uniform, and fiber content is $5 \%$, the concrete mass loss much lower than the other two contents. And antifreeze content is $6 \%$, it increases after the mass loss reduction, quality, larger changes, the laws of different fiber content in the quality of $3 \%$ for the loss and the other two points of a large margin. After analysis, we can see that the role of antifreeze bleed air caused by uneven and fiber content.

Concrete mass loss, when the fiber content reduces. Fiber volume is $3 \%$, $4 \%$ hours, the volume increase in antifreeze, concrete specimen mass loss rate of decline and antifreeze which content $4 \%$, $5 \%$ will change in a small range. The fiber content of the $5 \%$, the mass loss rate is the smallest.

\section{(4)Comprehensive analysis}

In summary, select 6\%o antifreeze and $5 \%$ fiber consumption, when the concrete frost resistance for the best. At the same time, according to analysis of relevant data, we can see that fiber content for the $5 \%(\mathrm{C} 1, \mathrm{C} 2, \mathrm{C} 3)$ and B3 Group compressive strength of concrete for $28 \mathrm{~d}$ is lower, it is difficult to ensure that the structural strength of concrete to meet the requirements. While the remaining groups of concrete benchmarks strength for $28 \mathrm{~d}$, freezing and thawing of concrete specimen strength and mass loss in Table 5 as below.

Table 5 Concrete benchmarks strength, strength loss rate and mass loss rate of $28 \mathrm{~d}$

\begin{tabular}{ccccc}
\hline Specimen No. & $\begin{array}{c}\text { 28d } \\
{[\mathrm{MPa}]}\end{array}$ & $\begin{array}{c}\text { baseline intensity } \\
{[\%]}\end{array}$ & $\begin{array}{c}\text { Strength loss rate } \\
\text { Mass loss rate [\%] }\end{array}$ & Options \\
\hline A1 & 33.77 & 12.81 & 0.25 & \\
\hline A2 & 34.87 & 11.93 & 0.22 & Program I \\
\hline A3 & 34.67 & 7.51 & 0.15 & Program II \\
\hline B1 & 33.23 & 12.05 & 0.24 & \\
\hline B2 & 33.13 & 10.82 & 0.23 & Program III \\
\hline
\end{tabular}


According to Table 5, it can be determined three options:

Program I, fiber content is $3 \%$ and antifreeze volume is 5\% (A2); Program II, fiber content is $3 \%$ and antifreeze volume is 6\% (A3); Program III, fiber content is $4 \%$ and antifreeze content is $4 \%$ (B2). We can see that the program I is the best program.

\section{Development of freeze-thaw resistance materials for the control structure of debris flow and mix design}

Through comparison and contrast the compressive strength of concrete specimen and mass loss, before or after freezing and thawing, we received two add admixture groups' higher performance. Because of large sections project along the Tianshan highway, requires large quantity of raw materials, which must be from the perspective of economic analysis and sets of programs on the feasibility and applicability (Table 6). After comparison and contrast, the second program of prices is more cost-effective for choice. If the special sections need for high strength concrete, we selected the first group program.

Table 6 Material price list of selection program

\begin{tabular}{ccccccccc}
\hline Material & $\begin{array}{c}\text { Cement } \\
(\mathrm{C})\end{array}$ & $\begin{array}{c}\text { Natural } \\
\text { sand }(\mathrm{S})\end{array}$ & $\begin{array}{c}\text { Lithotripsy } \\
(\mathrm{G})\end{array}$ & Antifreeze & $\begin{array}{c}\text { Super } \\
\text { plasticizer }\end{array}$ & Fiber & $\begin{array}{c}\text { Fly } \\
\text { Ash }\end{array}$ & $\begin{array}{c}\text { Total } \\
{[\text { Yuan }]}\end{array}$ \\
\hline Program1 & 86 & 46 & 80 & 45 & 0 & 42.55 & 60 & 317.003 \\
\hline Program2 & 86 & 46 & 80 & 36 & 0 & 42.55 & 60 & 308.003 \\
\hline Plain concrete & 86 & 46 & 80 & 0 & 9.5 & 0 & 60 & 281.503 \\
\hline
\end{tabular}

(Note: This price is based on Urumqi prices; even each cubic of raw materials prices is the total sum)

\section{Conclusions}

In the high-altitude and high cold of Tianshan areas, it assumes ordinary concrete life cycle is 6 years, According to the relevant conclusions of the pilot project, the freeze-thaw resistance of control structure (Program1) for debris flow about life cycle is 9 years, but the freeze-thaw resistance of control structure for ((Program1) debris flow control structure of the life cycle is 13.2 years. If control structure of debris flow need total volume of concrete for $9000 \mathrm{~m} 3$, According to a period of 25 years calculated, ordinary concrete needs 6,776,250 Yuan, but the freeze-thaw resistance of control structure concrete ((Program1) need for 6.75 million Yuan, the freeze-thaw resistance of control structure concrete ((Program2) need 4,815,341 Yuan, if add the construction and other costs, the total cost of freeze-thaw resistance of concrete were significantly less than the ordinary concrete (ordinary concrete has a short life cycle, need more cycle construction costs and other building maintenance costs).

\section{References:}

[1] N. Qian, Z. H. Wan. Sediment Movement Mechanics [M]. Beijing: China Science Press .1983

[2] H. K. CHen, H. M. Tang, Y. T. Ma. Research and Prevention of Highway Debris flow [M]. Beijing: China Communication Press .2004

[3] H. K. Chen, H. M. Tang, Y. T. Ma. Research and new prevention concept of large highway debris flow [J]. Highway . 2(2004)

[4] B. X. Tang, S. C. Zhang. Debris Flow Study [J]. Journal of Chinese Academy of Sciences Institute.1992, (2):119-123

[5] J. S. Wu, L. H. Tian. Study on the Debris Flow [J]. Mountain Research, 1996, 14 (2):26-33

[6] G. X. Chen,J. K. Wang. Debris Flow Control [M]. Beijing: China Railway Publishing House .1983:30-48 